\title{
Physical and biogeochemical spatial scales of variability in the East Australian Current separation from shelf glider measurements
}

\author{
Amandine Schaeffer ${ }^{1}$, Moninya Roughan ${ }^{1,3}$, Emlyn M. Jones ${ }^{2}$, and Dana White ${ }^{1}$ \\ ${ }^{1}$ Coastal and Regional Oceanography Lab, School of Mathematics and Statistics, University of \\ New South Wales, Sydney NSW, Australia \\ ${ }^{2}$ CSIRO Oceans and Atmosphere, Hobart, Tasmania, Australia \\ ${ }^{3}$ Sydney Institute of Marine Science, Mosman, NSW 2088, Australia \\ Correspondence to: Amandine Schaeffer (a.schaeffer@unsw.edu.au)
}

Received: 29 October 2015 - Published in Biogeosciences Discuss.: 15 December 2015

Revised: 20 February 2016 - Accepted: 9 March 2016 - Published: 31 March 2016

\begin{abstract}
In contrast to physical processes, biogeochemical processes are inherently patchy in the ocean, which affects both the observational sampling strategy and the representativeness of sparse measurements in data assimilating models. In situ observations from multiple glider deployments are analysed to characterize spatial scales of variability in both physical and biogeochemical properties, using an empirical statistical model. We find that decorrelation ranges are strongly dependent on the balance between local dynamics and mesoscale forcing. The shortest horizontal $(5-10 \mathrm{~km})$ and vertical $(45 \mathrm{~m})$ decorrelation ranges are for chlorophyll $a$ fluorescence, whereas those variables that are a function of regional ocean and atmosphere dynamics (temperature and dissolved oxygen) result in anisotropic patterns with longer ranges along $(28-37 \mathrm{~km})$ than across the shelf $(8-19 \mathrm{~km})$. Variables affected by coastal processes (salinity and coloured dissolved organic matter) have an isotropic range similar to the baroclinic Rossby radius (10-15 km).
\end{abstract}

\section{Introduction}

At the interface between oceanic and coastal processes, continental shelf regions are characterized by complex dynamics resulting from the interaction between different water masses at smaller spatial scales than the open ocean (Yoder et al., 1987). While wind, topography, or density-driven processes mostly influence the mixing and advection of the physical characteristics (temperature and salinity) of the shelf water masses, locally acting ecological processes are also determi- nant for biogeochemistry (Ballantyne et al., 2011). In particular, the numerous mechanisms driving phytoplankton distributions have been studied for many years, and highlight the complexity of these interactions (Martin, 2003). Biogeochemical (BGC) processes operate over a wide range of scales and thus need to be considered separately when investigating the dominant length scales of variability for the shelf water's properties (Pan et al., 2014).

The continental shelf off southeastern Australia (between 29 and $34^{\circ} \mathrm{S}$ ) is relatively narrow, between 16 and $70 \mathrm{~km}$ (mean of $37 \mathrm{~km}$ ) from the coastline to the $200 \mathrm{~m}$ isobath. The dynamics on the shelf are influenced both by local coastal processes and the episodic intrusion of the large-scale East Australian Current (EAC) and its eddies (Fig. 1, Schaeffer et al., 2013, 2014a). The EAC is the western branch of the subtropical gyre in the South Pacific. It is a warm and dynamic poleward flowing current, encroaching on the continental shelf of southeastern Australia between around $18^{\circ} \mathrm{S}$ (Ridgeway and Godfrey, 1994) and usually $30.7-32.4^{\circ} \mathrm{S}$ (Cetina-Heredia et al., 2014) where it bifurcates eastward, forming the Tasman Front. Further south, eddies are shed (Everett et al., 2012), leading to high variability in the velocity field and water masses on the shelf (Schaeffer et al., 2014b; Schaeffer and Roughan, 2015).

Previous studies have highlighted the high spatial heterogeneity of physical (Oke et al., 2008; Schaeffer and Roughan, 2015) and biochemical (Hassler et al., 2011) variables on this narrow shelf. Decorrelation timescales were quantified from in situ mooring observations at 30 and $34^{\circ} \mathrm{S}$ (Roughan et al., 2013), being of the order of hours for cross-shelf velocity 


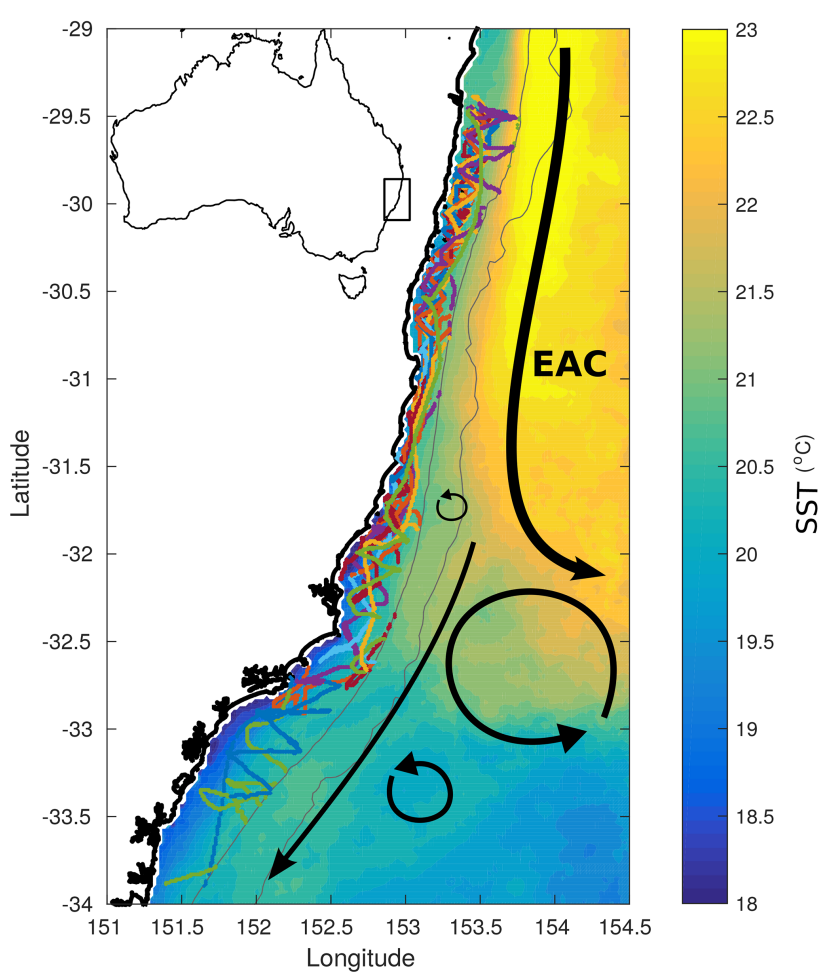

Figure 1. Monthly mean sea surface temperature (AVHRR L3S product) over southeastern Australia for October 2014. The coastline, 200, and $2000 \mathrm{~m}$ isobaths are shown. Glider tracks over the shelf (depth $<200 \mathrm{~m}$ ) are indicated by coloured lines. A schematic of the typical circulation is shown with the poleward flowing East Australian Current (EAC) bifurcating to the east around $32^{\circ} \mathrm{S}$, its weaker extension, anticyclonic, and cyclonic eddies.

to days and weeks for along-shelf flow and temperature, respectively. However, spatial scales of variability, which are essential for data assimilating models, have not been quantified.

Here we quantify for the first time the spatial scales of variability of both the physical and the BGC characteristics of the shelf water masses in the highly dynamic EAC separation zone. We use hydrographic measurements from 23 glider deployments along the coast (Sect. 2) to understand the variability amongst physical and BGC properties, the spatial anisotropy and the unresolved variance in the rich data set (Sect. 3). Finally the results are discussed in the context of their applicability to modelling and data assimilation, where the perennial issue of relating point-based measurements to model solutions is discussed (Sect. 4).

\section{Methods}

\subsection{The data set}

Ocean gliders are autonomous underwater vehicles which change their buoyancy to dive through the water column. Without propulsion, this vertical motion is transformed into horizontal momentum using the vehicle's wings, while its pitch controls the forward motion. During the resulting vertical sawtooth pattern through the water column, a wealth of scientific observations are recorded and analysed here. Physical and BGC measurements from 23 ocean glider deployments along the southeastern coast of Australia are used in this study. The glider missions span all seasons over 6 years, between 2008 and 2014, including results from both shallow-diving Slocum $(<200 \mathrm{~m})$ and deep-diving Seaglider $(<1000 \mathrm{~m})$ vehicles. The gliders were typically deployed at $29.4^{\circ} \mathrm{S}$ although some were deployed as far south as $33^{\circ} \mathrm{S}$ (Fig. 1 and Schaeffer and Roughan, 2015). Missions range 2-3 weeks to 3 months depending on the vehicle. The horizontal displacement between two dives increases with the depth of the dive, with median over ground distances from $130 \mathrm{~m}$ (for dives in $25-50 \mathrm{~m}$ of water) to $1100 \mathrm{~m}$ (in $150-200 \mathrm{~m}$ of water). The vertical resolution of observations is $<2 \mathrm{~m}$ due to the fast sampling frequency. Scientific measurements include depth, temperature, and salinity (from a Seabird-CTD), dissolved oxygen (DO, from Aanderaa or Seabird oxygen sensors), and optical parameters, chlorophyll $a$ fluorescence (excited/emitted wavelengths: 470/695 nm), coloured dissolved organic matter (CDOM, excited/emitted wavelengths: $370 / 460 \mathrm{~nm}$ ), and backscatter coefficient at $650-700 \mathrm{~nm}$ (from a WETLabs optical sensor).

Quality control for physical parameters (temperature and salinity) and DO are conducted following ARGO float standards (Wong et al., 2014), including a salinity spike correction due to the use of unpumped CTDs in early deployments. For bio-optical parameters, quality control is more challenging due to the instrument bio-fouling and the high temporal and spatial variability of the measurements. Sensors are calibrated approximately every 2 years. To check for sensor drift, performance tests are undertaken using purple and black solid standards pre- and post-deployment, as well as after cleaning the sensor from bio-fouling. These tests enable the identification and flagging of suspect measurements. A global range test is also conducted with a valid fluorescence maximum set to $50 \mathrm{mg} \mathrm{m}^{-3}$, similar to ARGO standards (Claustre, 2011). A valid regional maximum for CDOM is defined, based on all the shelf glider deployments, as the mean plus 10 times the standard deviation $(=8.0 \mathrm{ppb})$ to remove high outliers (reaching $250 \mathrm{ppb}$ ).

\subsection{Characterising spatial variability}

The semivariogram approach was first introduced in geostatistics (Journel and Huijbregts, 1978) to characterize the spatial variability of a sparsely distributed data set. It describes the average dissimilarity between measurements as a function of the distance separating them. This difference is generally small for measurements within close proximity, increasing with distance, until it does not depend on a spatial lag (decorrelated values) (Legaard and Thomas, 2007; Tortell et al., 2011). 
For a variable anomaly $Z(x)$, the semivariogram or structure function, $\gamma(h)$, is defined as half the mean square difference between values at a given separation $h$ :

$\gamma(h)=\frac{1}{2} \frac{1}{N} \sum\left([Z(x)-Z(x+h)]^{2}\right)$,

where the sum is over all $N$ pairs of observations that are separated by the distance $h$ in the $x$ direction. In order to take into account outliers in the distribution of the empirical anomalies Z, Cressie and Hawkins (1980) proposed a modified estimate of the structure function which is more robust when the anomaly fields deviate from being Gaussian:

$\gamma(h)=\frac{\frac{1}{2}\left(\frac{1}{N} \sum[Z(x)-Z(x+h)]^{1 / 2}\right)^{4}}{0.457+\frac{0.494}{N}}$.

In this equation, the power $1 / 2$ comes from a fourth-root of $[Z(x)-Z(x+h)]^{2}$ that reduces the skewness in the distribution, thereby approaching a Gaussian process. The fourth square acts to correct the scale and returns the same units as Eq. (1), while the denominator adjusts the bias resulting from the whole transformation. This estimate is more robust statistically in the sense that the mean can be applied to the new distribution. Compared to Eq. (1), the semivariogram is only slightly modified for the highest lags when using the robust Eq. (2), but the parameters (sill, range, and nugget that are investigated in Sect. 3) remain very similar.

The variables' anomalies are obtained by removing largescale patterns, resulting from the average of all glider measurements over predefined bins determined by latitude and depth, as in Schaeffer and Roughan (2015). This threedimensional mean state is then smoothed using a spline method before being removed from each observation. Both cross- and along-shelf semivariograms are calculated to investigate anisotropy, where $h=\Delta x$ is the zonal distance, or $h=\Delta y$ is the meridional distance, respectively. The crossshelf semivariance is calculated following Eq. (2) from measurement pairs located within $0.1^{\circ}(\sim 10 \mathrm{~km})$ of latitude. Similarly, the along-shelf semivariance $\gamma(h)$ is computed using observations within $0.1^{\circ}$ of longitude $(\sim 10 \mathrm{~km})$ from each other. In both cases the distance vector is discretized with intervals of $500 \mathrm{~m}$ and the time lag between pairs is limited to 1 day. The semivariograms are calculated in the horizontal plane at three depths: surface $(0-5 \mathrm{~m})$, mixed layer depth (MLD, 5-30 m, defined from the average profiles), or below the MLD at $50 \mathrm{~m}$. Finally, glider profiles are also used to analyse vertical scales by computing $\gamma(h)$ with $h=\Delta z$ (intervals of $1 \mathrm{~m}$ ).

The semivariance $\gamma(h)$ is computed from the trimmed mean (20\% outliers excluded) of measurements over all glider deployments, provided there are at least 10 (5 for CDOM across the shelf, see Sect. 3.4) different missions and more than 30 pairs for each spatial lag, to avoid seasonal bias or insignificant values. We then fit a mathematical spherical model (Doney et al., 2003) to the empirical semivariogram in order to extract the physical characteristics of the function, following:

$\left\{\begin{array}{ll}\sigma_{0}^{2}+\left(\sigma^{2}-\sigma_{0}^{2}\right)\left(\frac{3}{2} \frac{h}{r}-\frac{1}{2}\left(\frac{h}{r}\right)^{3}\right) & 0<h \leq r \\ \sigma^{2} & h>r\end{array}\right.$,

where $h$ is the distance between measurements, $\sigma^{2}$ is the sill, $\sigma_{0}^{2}$ is the nugget, and $r$ the range. (These variables are described physically in the example below.) Exponential and Gaussian models (Biswas and Si, 2013) were also tested but were less adequate in terms of sum of squared error (SE) and adjusted $R$-squared statistics for the fit of the empirical semivariogram.

\section{Results}

\subsection{Satellite-derived SST semivariogram}

By way of both example and validation, we calculate the cross-shelf semivariogram obtained from daily satellite remote-sensed sea surface temperature (SST) anomalies (Fig. 2). The spherical model (Eq. 3) is fitted to the empirical semivariance values calculated for cross-shelf lags over daily maps of SST in 2014. Only days with spatial coverage greater than $30 \%$ of the domain are considered. The physical characteristics extracted from the model are indicated in Fig. 2. The sill $\sigma^{2}$ reflects the constant background variability of the variable. It is reached at a specific distance, here $r=24 \mathrm{~km}$, which is referred to as the (decorrelation) range or the dominant length scale. For lags greater than this range, the two observations are considered randomly correlated spatially. The nugget, $\sigma_{0}^{2}$, is the semivariance obtained from the model at the origin. If different from 0 , it implies variability at shorter spatial scales than those resolved by the observations. This variability is either (a) real but unresolved, or (b) resulting from measurement errors. The semivariogram for SST (Fig. 2) shows very little nugget effect, showing the accuracy of the measurements and an adequate spatial resolution. As expected, the semivariance of the SST anomaly (the annual mean was subtracted) differs with seasonality, as shown by the monthly empirical semivariograms (coloured dots in Fig. 2). Austral summer and autumn months are characterized by a sharper increase in the SST variance with greater variability in sills, due to more pronounced spatial temperature gradients. However, the semivariogram range is similar, with dominant cross-shelf scales between 18 and $32 \mathrm{~km}$ (not shown). The semivariogram reaches a plateau for all months, with the exception of January, suggesting a trend of longer scales (Yoder et al., 1987) and a limitation of the method.

\subsection{Sill: in situ spatial variance}

Semivariance values from glider measurements are analysed based on the values of the sill in each of the semivariograms shown in Fig. 3. Temperature, dissolved oxygen (DO), and, 


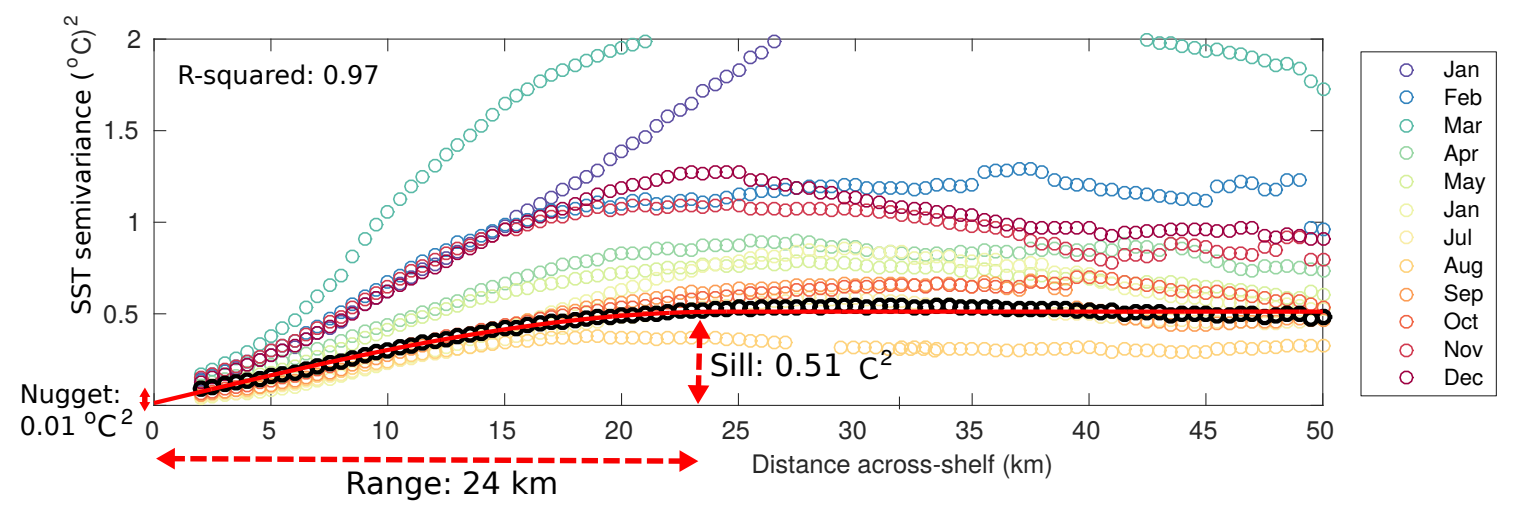

Figure 2. Cross-shelf empirical semivariogram estimated from daily SST over the southeastern Australian shelf (depth $<200 \mathrm{~m}, 29-34^{\circ} \mathrm{S}$, AVHRR L3S product) for 2014 (black bold dots) and for each month in 2014 (coloured dots). The spherical model (red line, $R$ squared of 0.97 for the fit) and resulting parameters (range, sill, nugget) are shown for 2014 semivariance.

to a lesser extent, coloured dissolved organic matter (CDOM) and salinity, are characterised by a greater variance in the vertical than in the horizontal (see the different $y$ axis). In contrast, chlorophyll $a$ fluorescence shows comparable variability in all directions. Focusing on horizontal sills (Fig. 3 middle and left), the highest variance for salinity and CDOM occurs at the surface in agreement with the influence of riverine input. The cross-shelf sill for DO is greater at $50 \mathrm{~m}$ than at the surface, suggesting more spatial variability due to biophysical processes (remineralization, respiration, or bottom water uplift) than resulting from gas exchange with the atmosphere. Chlorophyll $a$ fluorescence shows little variance at $50 \mathrm{~m}$ depth due to light limitation preventing biological activity. The highest horizontal sill for temperature appears below the MLD along the shelf, in agreement with the large latitudinal gradients in bottom temperature evidenced by Schaeffer and Roughan (2015). The surface temperature sill is smaller when measured by the gliders (Fig. 3) than by satellite (Fig. 2), possibly due to different measurement depth in situ $0-5 \mathrm{~m}$ vs. skin SST), or seasonality, as glider deployments are more numerous in winter. Nevertheless, the crossshelf dominant length scales are in good agreement in the two data sets, with ranges of 25 and $19 \mathrm{~km}$, respectively.

\subsection{Range: in situ scales of variability}

Cross-shelf, along-shelf, and vertical ranges from the semivariograms are presented in Fig. 3 and summarized in Table 1. Spatial scales highlight different directional patterns between the parameters. Horizontal scales for salinity and CDOM are 9-15 km, 5-10 km for chlorophyll $a$ fluorescence, similar across and along the shelf. Mean temperature scales across the shelf are $18-19 \mathrm{~km}$ at the surface and in the MLD, only $14 \mathrm{~km}$ at $50 \mathrm{~m}$. Scales found along the shelf are greater, being $28-29$ and $37 \mathrm{~km}$, respectively. This directional anisotropy for temperature is in agreement with the geometry of the shelf and the influence of the EAC at the shelf break (Fig. 1). Schaeffer and Roughan (2015) and Oke et al. (2008) both evidenced greater temperature gradients across than along the shelf, based on satellite, model and glider data sets. This directional anisotropy is also evident in density (not shown), which has been shown to be mostly temperature driven (Schaeffer et al., 2014b), and even more intensified for DO. While DO is characterized by dominant cross-shelf scales similar to salinity and CDOM $(8-15 \mathrm{~km})$, the along-shelf spatial variability seems to be linked to the shallow EAC water mass, resulting in decorrelation scales of 27 to $35 \mathrm{~km}$ (surface and MLD) similar to temperature. Chlorophyll $a$ fluorescence has the smallest characteristic length scales both across and along the shelf, but also in the vertical. Measurements of fluorescence are decorrelated for depth lags greater than $46 \mathrm{~m}$, in agreement with shallow (near surface) chlorophyll blooms. Vertical length scales for DO and CDOM $(57-58 \mathrm{~m})$, are less than those for temperature and salinity ( $62 \mathrm{~m}$ and $66 \mathrm{~m}$, respectively). The second peak in semivariance (at $80-100 \mathrm{~m}$ for temperature, salinity and DO, Fig. 3, right) indicates an anti-correlation for these lags (Legaard and Thomas, 2007). Negative correlation coefficients reaching -0.6 were previously observed from moored autumnal temperature observations in $100 \mathrm{~m}$ water depth at $30^{\circ} \mathrm{S}$ (Roughan et al., 2013) and attributed to simultaneous heating source in the surface layers and cooling at depth due to EAC encroachments and slope water uplift. Our results suggest that these current-driven uplifts are associated with a signature in salinity and DO.

\subsection{Nugget: in situ unresolved variance}

The fraction of resolved and unresolved variance is estimated from the semivariogram parameters, the sill and nugget, respectively. A nugget occurs when the difference between the two closest measurements is greater than zero, and can be seen at the origin of the semivariogram. Overall, the high density glider observations capture most of the spatial ocean 

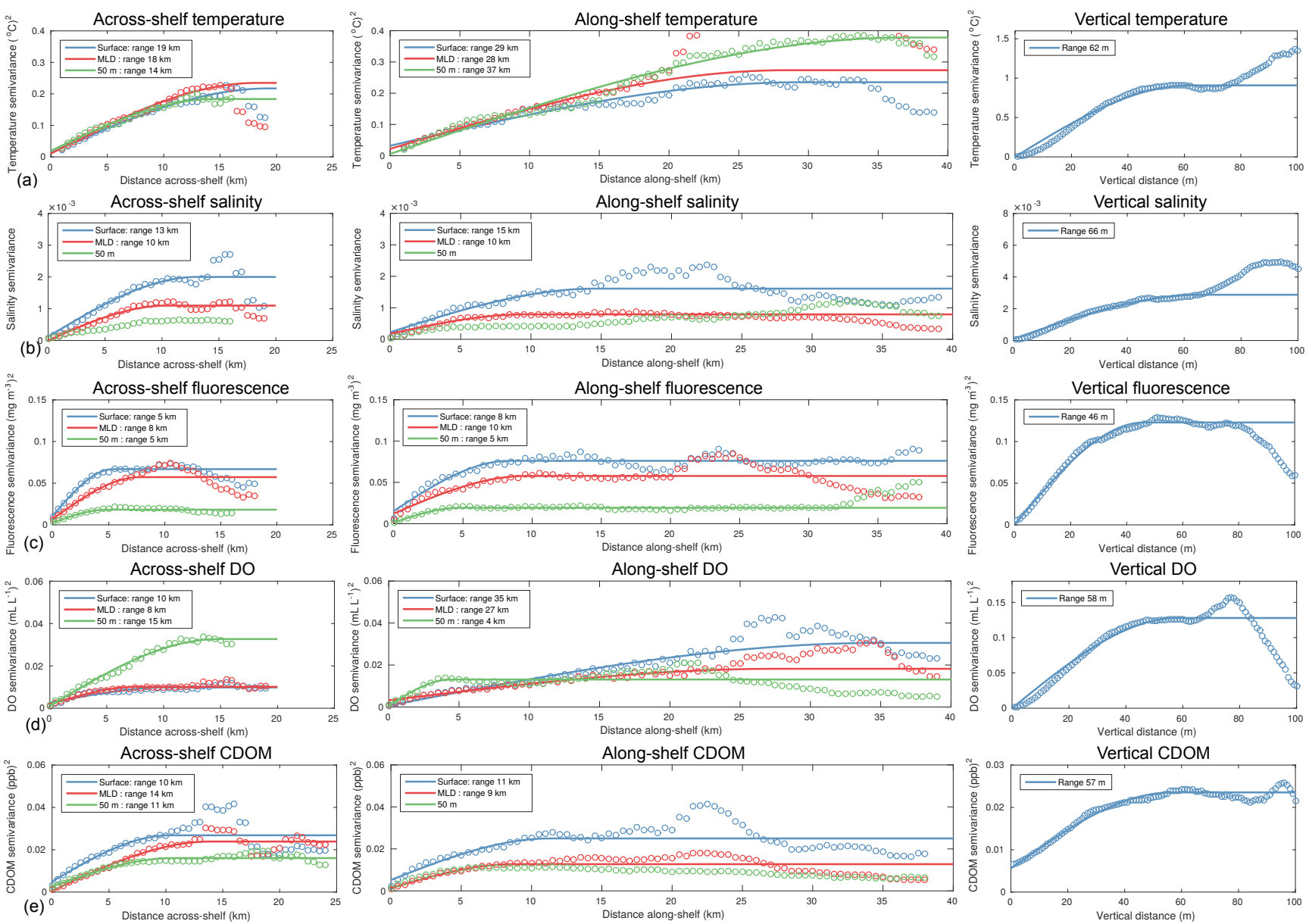

Figure 3. Cross-shelf (left), along-shelf (middle) and vertical (right) empirical semivariograms estimated from glider measurements of (a) temperature, (b) salinity, (c) chlorophyll $a$ fluorescence, (d) DO, and (e) CDOM. Spherical models are shown by the solid lines and the resulting spatial ranges are indicated in the insert for successful fits. Blue, red, green symbols for horizontal semivariograms correspond to surface (0-5 m), MLD (5-30 m), and $50 \mathrm{~m}$ measurements, respectively.

variability. The advantage of this sampling strategy is that nearly all the vertical variance is resolved for most of the parameters (ratio $\sigma_{0}^{2} / \sigma^{2} \sim 0-3 \%$, Table 1) due to the high sampling frequency of the gliders compared to their vertical displacement velocity. The only exception is for CDOM with the nugget being $24 \%$ of the total variance (Fig. 3 and Table 1). Horizontal variability is well resolved for temperature and salinity with ratios $\sigma_{0}^{2} / \sigma^{2} \leq 10 \%$ across the shelf, mostly $\leq 14 \%$ along the shelf. Nuggets for BGC parameters are higher, reaching $27 \%$ of the sill. While high nuggets for fluorescence and DO can be attributed to horizontal subscale unresolved biological activity, CDOM data sets might also suffer from measurement errors and quality control issues, as suggested by the high nugget effect in the vertical, the large outliers, and the larger amount of cross-shelf lags necessary for the successful fit of a mathematical model (see Sect. 2 and Fig. 3e).

\section{Discussion}

This study combines in situ measurements from multiple glider deployments between 2008 and 2014 on the southeastern Australian continental shelf, to provide insight into the surface and subsurface structure of the water mass dynamics, including the influence of the EAC, upwelling and freshwater inputs. Analysis of length-scale-dependent variability demonstrates that much of the spatial variance in physical and BGC parameters typically occurs at scales ranging $5 \mathrm{~km}$ for chlorophyll $a$ fluorescence to $\sim 35 \mathrm{~km}$ for along-shelf temperature. In this study, the length scales were averaged from data obtained over $2^{\circ}$ of latitude; however, we expect more regional variability resulting from the different latitudinal regimes evidenced by Schaeffer and Roughan (2015), driven by the mesoscale circulation. In addition, we expect that spatial scales may vary seasonally, particularly in the biological parameters. This will be tested when we have sufficient data in each season. 
Table 1. Spatial scales of variability for spherical fit to semivariograms for different parameters and depths across, along the shelf and along the vertical. The range, percentage ratio of the nugget to the sill $\left(\sigma_{0}^{2} / \sigma^{2}\right)$, and $R$ squared for the model fit to experimental values are indicated (ranges with ${ }^{\text {a }}$ correspond to $R$ squared $<0.7$ ). Blanks indicate unsuccessful fit to the spherical model.

\begin{tabular}{|c|c|c|c|c|c|c|c|}
\hline & & & Temperature & Salinity & Fluorescence & DO & $\mathrm{CDOM}$ \\
\hline \multirow{9}{*}{$\begin{array}{l}\frac{4}{0} \\
\frac{0}{0} \\
\dot{1} \\
\dot{0} \\
0 \\
0\end{array}$} & \multirow{3}{*}{ Surface } & range & $19 \mathrm{~km}$ & $13 \mathrm{~km}$ & $5 \mathrm{~km}$ & $10 \mathrm{~km}$ & $10 \mathrm{~km}^{\mathrm{a}}$ \\
\hline & & ratio $\sigma_{0}^{2} / \sigma^{2}$ & $6 \%$ & $6 \%$ & $17 \%$ & $27 \%$ & $19 \%$ \\
\hline & & $R$-squared fit & 0.96 & 0.94 & 0.89 & 0.85 & 0.49 \\
\hline & \multirow{3}{*}{ MLD } & range & $18 \mathrm{~km}$ & $10 \mathrm{~km}$ & $8 \mathrm{~km}^{\mathrm{a}}$ & $8 \mathrm{~km}$ & $14 \mathrm{~km}$ \\
\hline & & ratio $\sigma_{0}^{2} / \sigma^{2}$ & $4 \%$ & $0 \%$ & $13 \%$ & $18 \%$ & $2 \%$ \\
\hline & & $R$-squared fit & 0.92 & 0.83 & 0.58 & 0.89 & 0.96 \\
\hline & \multirow{3}{*}{$50 \mathrm{~m}$} & range & $14 \mathrm{~km}$ & & $5 \mathrm{~km}$ & $15 \mathrm{~km}$ & $11 \mathrm{~km}$ \\
\hline & & ratio $\sigma_{0}^{2} / \sigma^{2}$ & $10 \%$ & & $15 \%$ & $4 \%$ & $17 \%$ \\
\hline & & $R$-squared fit & 0.97 & & 0.73 & 0.98 & 0.88 \\
\hline \multirow{7}{*}{$\begin{array}{l}\frac{}{0} \\
\frac{1}{4} \\
0 \\
00 \\
0 \\
\frac{0}{2}\end{array}$} & \multirow{3}{*}{ Surface } & range & $29 \mathrm{~km}$ & $15 \mathrm{~km}^{\mathrm{a}}$ & $8 \mathrm{~km}$ & $35 \mathrm{~km}$ & $11 \mathrm{~km}^{\mathrm{a}}$ \\
\hline & & ratio $\sigma_{0}^{2} / \sigma^{2}$ & $14 \%$ & $14 \%$ & $20 \%$ & $2 \%$ & $21 \%$ \\
\hline & & $R$-squared fit & 0.93 & 0.52 & 0.83 & 0.90 & 0.56 \\
\hline & \multirow{3}{*}{ MLD } & range & $28 \mathrm{~km}$ & $10 \mathrm{~km}$ & $10 \mathrm{~km}^{\mathrm{a}}$ & $27 \mathrm{~km}$ & $9 \mathrm{~km}^{\mathrm{a}}$ \\
\hline & & ratio $\sigma_{0}^{2} / \sigma^{2}$ & $8 \%$ & $23 \%$ & $21 \%$ & $18 \%$ & $10 \%$ \\
\hline & & $R$-squared fit & 0.99 & 0.93 & 0.53 & 0.96 & 0.27 \\
\hline & $50 \mathrm{~m}$ & $\begin{array}{l}\text { range } \\
\text { ratio } \sigma_{0}^{2} / \sigma^{2} \\
R \text {-squared fit }\end{array}$ & $\begin{array}{c}37 \mathrm{~km} \\
1 \% \\
0.97 \\
\end{array}$ & & $\begin{array}{c}5 \mathrm{~km} \\
8 \% \\
0.87\end{array}$ & $\begin{array}{c}4 \mathrm{~km}^{\mathrm{a}} \\
5 \% \\
0.33\end{array}$ & \\
\hline : & & $\begin{array}{l}\text { range } \\
\text { ratio } \sigma_{0}^{2} / \sigma^{2} \\
R \text {-squared fit }\end{array}$ & $\begin{array}{c}62 \mathrm{~m} \\
0 \% \\
0.97\end{array}$ & $\begin{array}{c}66 \mathrm{~m} \\
3 \% \\
0.98\end{array}$ & $\begin{array}{c}46 \mathrm{~m} \\
1 \% \\
0.99\end{array}$ & $\begin{array}{c}58 \mathrm{~m} \\
0 \% \\
0.98\end{array}$ & $\begin{array}{l}57 \mathrm{~m} \\
24 \% \\
0.99\end{array}$ \\
\hline
\end{tabular}

As for all statistics, limitations arise from the amount of data used (especially along the shelf where the data density is smaller) and contamination of the data set (for instance CDOM). In geostatistics, uneven spatial distribution of the observations over the analysed area can be a limitation as well but remains difficult to quantify. The major advantage of the semivariogram method used is that it can be applied to sparse data set like glider observations, as opposed to spatial autocorrelations, for instance. It allows objective comparison of interesting parameters (range, sill, nugget) for different variables, directions, and depths. In this study, the results compare well when using different statistical fits, and are consistent with expected outcomes based on previous knowledge of local dynamics and related studies in other regions.

\subsection{Related studies}

From a global analysis of satellite-derived surface data, Doney et al. (2003) found comparable small-scale variability for biology and physics. However, they were not able to characterize scales $<15 \mathrm{~km}$ based on the satellite products used. Here we find that BGC distribution occurs predominantly at submesoscales (5-14 km for chlorophyll $a$, CDOM), while scales for temperature are larger $(14-37 \mathrm{~km})$. These short scales of variability for BGC are in agreement with the effect of nutrient cycling, reproductive rate, and community interaction (e.g. grazing pressure from zooplankton) that can lead to patches of 5-10 km (Ballantyne et al., 2011; Denman et al., 1977; Goebel et al., 2014). According to Mahadevan and Campbell (2002), the fine-scale patchy distribution of phytoplankton is linked to the short characteristic time in response to disturbance in their concentration, as opposed to the longer time for temperature to adjust to external forcing. We find temperature horizontal scales $(14-37 \mathrm{~km})$ that are of the same order of magnitude as over the Malvinas Current region, derived from SST (20-47 km, Tandeo et al., 2014) or over the Middle Atlantic Bight from in situ glider observations (10$35 \mathrm{~km}$, Todd et al., 2013). The anisotropic shape of the temperature variance is consistent with a highly dynamic circulation (Tandeo et al., 2014), here driven by the EAC, characterized by a greater signature in temperature than in salinity. Spatial variability in salinity is predominantly isotropic and similar to CDOM with decorrelation length scales of 9$15 \mathrm{~km}$, corresponding to the first Rossby baroclinic radius of deformation (12-15 km based on local moored observation, Schaeffer et al., 2014b), and high surface variance, suggesting a predominant influence of coastal processes and river input. 


\subsection{Drivers of variability in a modelling perspective}

Assuming that there is no first order feedback from the biology to the physics, we can think of the physics variables $\mathbf{X}=T, S$ (temperature and salinity) being a function of internal dynamics ( $I$, e.g. mixing), atmospheric forcing $(A)$, coastal buoyancy forcing arising from river discharge $(R)$, friction due to shallow bathymetry $(F)$ and open ocean forcing (e.g. tidal, geostrophy), and water masses $(O)$. Therefore, the state of the model at some spatial location " $s$ " at time $t$ is given by:

$\mathbf{X}(s, t)=f(I, A, R, F, O)$,

where $f(I, A, R, F, O)$ for the physical variables can be solved numerically in various hydrodynamic models. For the state variable of temperature, we assume that there is little effect from river input in this region (e.g. water coming in is about the same temperature as the surface layer), while the effect from coastal processes is large for salinity. Therefore, Eq. (4) simplifies to:

$T(s, t)=f(I, A, F, O)$

$S(s, t)=f(I, A, R, F, O)$.

Given that both $T$ and $S$ are subjected to the same advection and diffusion equations, but differ only in the source/sink and boundary terms of $f(A), f(R)$, and $f(O)$, those are the major drivers for the difference in the along shelf sills and differences in the nugget. Salinity varies over shorter length scales due to river input and the markedly different freshwater inputs from various catchment sizes along the coast, whereas temperature is largely controlled by the regional-scale EAC forcing and the relatively smooth atmospheric forcing applied which varies over spatial scales of $50 \mathrm{~km}$ or more. A similar approach can be applied to the BGC variables, but $f(I)$ is more complicated as it includes the turnover of biomass/nutrients between different plankton functional types or nutrient pools. However, ultimately, one would expect $f(I)$ to introduce variability at scales equal to or less than those seen in salinity. This hypothesis is supported by the ranges reported in the chlorophyll $a$ fluorescence and CDOM variables, which are biologically derived. However, as CDOM can also be introduced into the coastal ocean via river plumes and has a similar sill structure to salinity, we suggest that the CDOM measured by the glider is largely due to river discharge. The DO distribution in the surface layer is largely a function of air-sea exchange rather than primary production and will have similar variability to temperature due to the forcing mechanism. However, below the mixed layer, DO is function of the remineralization rate and also vertical mixing/exchange with surface water, explaining the shorter decorrelation range in DO found below the mixed layer.

\subsection{Observing system design}

The length scales calculated here can be used to guide the design of ocean observing systems, in particular to answer questions related to the observation density needed to resolve along and cross-shore variability in both the physical and biological parameters. The temperature anisotropy in our results, consistent with findings of Oke and Sakov (2012) and Jones et al. (2015), shows that the required observation density will vary along and across the shelf. Thus, highresolution cross-shelf mooring or glider lines every $Y \mathrm{~km}$ are more useful than simply a glider endurance line or equally spaced moorings. The distance $Y$ can be initially derived from satellite observations, or determined after a number of glider missions. In contrast, the understanding of BGC variability, characterized by short isotropic length scales, will require high spatial resolution observations (e.g. gliders) to determine the representativeness of the measurements.

\subsection{Data assimilation}

There are a variety of data assimilation systems based upon two broad approaches, ensemble methods (e.g. Oke et al., 2008, Jones et al., 2012) and variational methods, that minimize a cost function (e.g. Moore, 2011). Regardless of the approach used, assumptions are made about the spatial footprint of an observation, for which a key parameter is the decorrelation length scale. Within the ensemble (e.g. Oke et al., 2008) and hybrid (Pan et al., 2011) data assimilation approaches, covariance localization (Sakov and Bertino, 2011) is used to increase the rank of the background error covariance matrix. The anisotropic (along-shelf and crossshelf) ranges presented in this study and method used to derive them, allow for the direct calibration of the decorrelation scales enforced within most data assimilation systems that are currently in use. Additionally, estimates of how these decorrelation scales vary in time are also available (e.g. Fig. 2), suggesting that an optimally tuned data assimilation system should allow for temporal variation in the localization or provide an assessment of the temporal variability of the ensemble from an ensemble Kalman filter (EnKF) system.

The results from this study also allow us to partly answer the question of how to relate a point-based observation with the output from a numerical model, which assumes the average concentration of a variable within a model cell $X_{\text {mod }}$. If we take a Bayesian view stating that we observe some true state variable with error (e.g. Parslow et al., 2013), this can be written as:

$X_{\mathrm{obs}}=X_{\text {true }}+\epsilon_{m}+\epsilon_{v}$,

where $X_{\text {obs }}$ is the observed variable, $X_{\text {true }}$ is the true unknown value of the variable, $\epsilon_{m}$ is the instrument error, and $\epsilon_{v}$ is the sampling error due to unresolvable small-scale variability. The observation is then related to the modelled vari- 
able by:

$X_{\mathrm{mod}}=X_{\mathrm{obs}}+\epsilon_{\mathrm{r}}$,

where $\epsilon_{\mathrm{r}}$ is typically referred to as the representation error (Oke and Sakov, 2008) associated with difference in kind (e.g. measuring fluorescence, but modelling biomass), or averaging across a model grid cell that contains a point measurement. Assuming $\epsilon_{m}$ is known from calibration studies, results of studies like that presented here allow us to explore the characteristics of $\epsilon_{v}$ and $\epsilon_{\mathrm{r}}$. For a particular variable, we can assume that the nugget is approximately equal to $\epsilon_{v}$ and given a priori information about a model grid, the spherical model applied to the semivariogram can then also be used to provide an empirical estimate for $\epsilon_{\mathrm{r}}$.

To this end, the results of this study allow us to characterise the length scales of the physical and BGC properties on the shelf and relate variability to the dynamical drivers, but additionally, the methodology developed here can be directly used to improve observing system design, and to tune key data assimilation parameters that are presently poorly understood.

\section{Data availability}

All data sets are freely available at https://imos.aodn.org.au/ imos123/home.

Acknowledgements. IMOS is an initiative of the Australian Government being conducted as part of the National Collaborative Research Infrastructure Strategy. Assistance with logistical and technical support for this project has been provided by ANFOG Australian Facility for Ocean Gliders and the NSW-IMOS glider team.

Edited by: T. Treude

\section{References}

Ballantyne, F., Schofield, O. M., and Levin, S.: The emergence of regularity and variability in marine ecosystems: the combined role of physics, chemistry and biology, Sci. Mar., 75, 719-731, doi:10.3989/scimar.2011.75n4719, 2011.

Biswas, A. and Si, B. C.: Model Averaging for Semivariogram Model Parameters, Advances in Agrophysical Research, 4, 8196. doi:10.5772/52339, 2013.

Cetina-Heredia, P., Roughan, M., van Sebille, E., and Coleman, M. A.: Long-term trends in the east australian current separation latitude and eddy driven transport. J. Geophys. Res.-Oceans, 119, 4351-4366, doi:10.1002/2014JC010071, 2014.

Claustre, H.: Bio-optical sensors on argo floats. reports of the international ocean-colour coordinating group, no. 11, ioccg. Tech. rep., IOCCG, Dartmouth, Canada, 2011.

Cressie, N. and Hawkins, D.: Robust Estimation Of The Variogram, J. Int. Ass. Math. Geol., 12, 115-125, doi:10.1007/BF01035243, 1980.
Denman, K., Okubo, A., and Platt, T.: The chlorophyll fluctuation spectrum in the sea. Limnol. Oceanogr., 22, 1033-1038, doi:10.4319/lo.1977.22.6.1033, 1977.

Doney, S. C., Glover, D. M., McCue, S. J., and Fuentes, M.: Mesoscale variability of sea-viewing wide field-ofview sensor (seawifs) satellite ocean color: Global patterns and spatial scales, J. Geophys. Res.-Oceans, 108, 3024, doi:10.1029/2001JC000843, 2003.

Everett, J. D., Baird, M. E., Oke, P. R., and Suthers, I. M.: An avenue of eddies: Quantifying the biophysical properties of mesoscale eddies in the Tasman Sea, Geophys. Res. Lett., 39, L16608, doi:10.1029/2012GL053091, 2012.

Goebel, N. L., Frolov, S., and Edwards, C. A.: Complementary use of wave glider and satellite measurements: Description of spatial decorrelation scales in chl $a$ fluorescence across the pacific basin, Methods in Oceanography, 10, 90-103, doi:10.1016/j.mio.2014.07.001, 2014.

Hassler, C., Djajadikarta, J., Doblin, M., Everett, J., and Thompson, P.: Characterisation of water masses and phytoplankton nutrient limitation in the east australian current separation zone during spring 2008, Deep Sea Res. Pt. II, 58, 664-677, doi:10.1016/j.dsr2.2010.06.008, 2011.

Jones, E. M., Oke, P. R., Rizwi, F., and Murray, L. M.: Assimilation of glider and mooring data into a coastal ocean model, Ocean Model., 47, 1-13, doi:10.1016/j.ocemod.2011.12.009, 2012.

Jones, E. M., Doblin, M. A., Matear, R., and King, E.: Assessing and evaluating the ocean-colour footprint of a regional observing system, J. Marine Syst., 143, 49-61, doi:10.1016/j.jmarsys.2014.10.012, 2015.

Journel, A. G. and Huijbregts, C. J.: Mining geostatistics, Academic Press London, UK and New York, USA, 600 pp., 1978.

Legaard, K. R. and Thomas, A. C.: Spatial patterns of intraseasonal variability of chlorophyll and sea surface temperature in the california current, J. Geophys. Res.-Oceans, 112, C09006, doi:10.1029/2007JC004097, 2007.

Mahadevan, A. and Campbell, J. W.: Biogeochemical patchiness at the sea surface, Geophys. Res. Lett., 29, 32-1-32-4, doi:10.1029/2001GL014116, 2002.

Martin, A.: Phytoplankton patchiness: the role of lateral stirring and mixing, Prog. Oceanogr., 57, 125-174, doi10.1016/S0079-6611(03)00085-5, 2003.

Moore, A. M., Arango, H. G., Broquet, G., Edwards, C., Veneziani, M., Powell, B., Foley, D., Doyle, J. D., Costa, D., and Robinson, P.: The Regional Ocean Modeling System (ROMS) 4dimensional variational data assimilation systems: Part II - Performance and application to the California Current System, Prog. Oceanogr., 91, 50-73, doi:10.1016/j.pocean.2011.05.003. 2011

Oke, P. and. Sakov, P: Assessing the footprint of a regional ocean observing system, J. Marine Syst., 105-108, 30-51, doi:10.1016/j.jmarsys.2012.05.009, 2012.

Oke, P. R. and Sakov, P.: Representation Error of Oceanic Observations for Data Assimilation, J. Atmos. Ocean. Techn., 25, 1004, doi:10.1175/2007JTECHO558.1, 2008.

Oke, P. R., Brassington, G. B., Griffin, D. A., and Schiller, A.: The bluelink ocean data assimilation system (bodas), Ocean Model., 21, 46-70, doi:10.1016/j.ocemod.2007.11.002, 2008.

Pan, C., Yaremchuk, M., Nechaev, D., and Ngodock, H.: Variational assimilation of glider data in Monterey Bay, J. Marine Res., 69, 331-346, doi:10.1357/002224011798765259, 2011. 
Pan, C., Zheng, L., Weisberg, R. H., Liu, Y., and Lembke, C. E.: Comparisons of different ensemble schemes for glider data assimilation on west florida shelf, Ocean Model., 81, 13-24, doi:10.1016/j.ocemod.2014.06.005, 2014.

Parslow, J., Cressie, N., Campbell, E. P., Jones, E., and Murray, L.: Bayesian learning and predictability in a stochastic nonlinear dynamical model, Ecol. Appl., 23, 679-698, 2013.

Ridgeway, K. and Godfrey, J.: Mass and heat budgets in the east australian current: a direct approach, J. Geophys. Res., 99, 32313248, 1994.

Roughan, M., Schaeffer, A., and Kioroglou, S.: Assessing the design of the nsw-imos moored observation array from 2008-2013: Recommendations for the future, Oceans - San Diego, CA, USA, 23-27 September 2013 , 1-7, 2013.

Sakov, P. and Bertino, L.: Relation between two common localisation methods for the EnKF, Computat. Geosci., 15, 225-237, doi:10.1007/s10596-010-9202-6, 2011.

Schaeffer, A. and Roughan, M.: Influence of a western boundary current on shelf dynamics and upwelling from repeat glider deployments, Geophys. Res. Lett., 42, 121-128, doi:10.1002/2014GL062260, 2015.

Schaeffer, A., Roughan, M., and Morris, B.: Cross-shelf dynamics in a western boundary current. implications for upwelling, J. Phys. Oceanogr., 43, 1042-1059, doi:10.1175/JPO-D-12-0177.1, 2013

Schaeffer, A., Roughan, M., and Morris, B.: Corrigendum crossshelf dynamics in a western boundary current. implications for upwelling, J. Phys. Oceanogr., 44, 2812-2813, doi:10.1175/JPOD-14-0091.1, 2014a.
Schaeffer, A., Roughan, M., and Wood, J. E.: Observed bottom boundary layer transport and uplift on the continental shelf adjacent to a western boundary current, J. Geophys. Res.-Oceans, 119, 4922-4939, doi:10.1002/2013JC009735, 2014b.

Tandeo, P., Autret, E., Chapron, B., Fablet, R., and Garello, R.: SST spatial anisotropic covariances from metop-avhrr data, Remote Sens. Environ., 141, 144-148, doi:10.1016/j.rse.2013.10.024, 2014.

Todd, R. E., Gawarkiewicz, G. G., and Owens, W. B.: Horizontal scales of variability over the middle atlantic bight shelf break and continental rise from finescale observations, J. Phys. Oceanogr., 43, 222-230, doi:10.1175/JPO-D-12-099.1, 2013.

Tortell, P., Gueguen, C., Long, M., Payne, C., Lee, P., and DiTullio, G.: Spatial variability and temporal dynamics of surface water $p \mathrm{CO}_{2}, \mathrm{O}_{2} / \mathrm{Ar}$ and dimethylsulfide in the Ross Sea, Antarctica, Deep Sea Res. Pt. I,, 58, 241-259, doi:10.1016/j.dsr.2010.12.006, 2011.

Wong, A., Keeley, R., and Carval, T.: Argo quality control manual. Tech. rep., Argo Data Management Team, available at: doi:10.13155/33951, 2014.

Yoder, J. A., McClain, C. R., Blanton, J. O., and Oeymay, L.Y.: Spatial scales in czcs-chlorophyll imagery of the southeastern u.s. continental shelf. Limnol. Oceanogr., 32, 929-941, doi:10.4319/lo.1987.32.4.0929, 1987. 